functional residual capacity (FRC) and LCI measurements at varying degrees of DS and ventilation heterogeneity. An estimate was also made of the effects in children, based upon extrapolation adult clinical data.

Results Excreted nitrogen had a small effect on accuracy of FRC $(1.8 \%)$ in the healthy adult model. The error in LCI calculated with true FRC was greater (6.3\%), and excreted nitrogen contributed $21 \%$ of the total nitrogen concentration at the end of the washout. Increasing DS caused further increase in measurement error, whilst increasing ventilation heterogeneity caused a bell shaped curve with initially increasing error falling again as ventilation heterogeneity approached a maximum. LCI was increased by $6-13 \%$ in a CF child model, and excreted nitrogen increased the end of washout nitrogen concentration by $24-49 \%$.

Conclusions Excreted nitrogen appears to have complex but clinically significant effects on washout progress, particularly in the presence of abnormal gas mixing. This may explain much of the previously described differences in washout outcomes between $\mathrm{SF}_{6}$ and nitrogen. Caution should be applied in applying conclusions derived from using one tracer gas to another.

\section{S42 EFFECT OF IRON DEFICIENCY ON OXYGEN TRANSPORT IN HYPOXAEMIC PATIENTS: IMPLICATIONS FOR HAEMODYNAMICS AND CLINICAL MANAGEMENT}

V Santhirapala, LC Williams, HC Tighe, JE Jackson, CL Shovlin; Imperial College London, London, UK

\subsection{6/thoraxinl-2013-204457.49}

Background Oxygen transport in the blood depends not only upon oxygen partial pressure (or saturation, $\mathrm{SaO}_{2}$ ), but also the concentration of haemoglobin to which oxygen binds, and blood volume in any given period. In current clinical studies and guidelines, it is rare for these components to be discussed together.

Methods An observational cohort study was performed in 165 consecutive unselected patients with pulmonary arteriovenous malformations, including 98 before and after embolisation. 159 (96\%) had hereditary haemorrhagic telangiectasia (HHT). Prior to statistical analyses, patients were stratified by self-reported exercise tolerance, and serum iron/ferritin.

Results Patients were aged 17-87 (median 49)ys, with median $\mathrm{SaO}_{2}$ 95\% (range 78.5-99\%) Many had biochemical/haematinic evidence of iron deficiency, predominantly attributable to HHT-blood loss, but several had undergone venesection for secondary polycythaemia, as recommended in current UK haematological guidelines. Haemoglobin ranged from 7.7-20.9g/ $\mathrm{dl}$ (median $14.1 \mathrm{~g} / \mathrm{dl}$ ), and was higher in patients with lower $\mathrm{SaO}_{2}$ : For every $1 \%$ fall in $\mathrm{SaO}_{2}$, haemoglobin rose on average, by $0 \cdot 82 \mathrm{~g} / \mathrm{dl}(\mathrm{p}<0 \cdot 0001) . \mathrm{SaO}_{2}$ explained only $0 \cdot 1 \%$ of the variance in oxygen carriage per unit blood volume. Embolisation treatment increased $\mathrm{SaO}_{2}$ (median $+2 \cdot 5 \%$ ), but usual subsequent haemoglobin falls restored oxygen carriage/unit volume. Concurrent iron deficiency reduced erythrocyte haemoglobin content. Secondary erythrocytosis was achievable with low ferritin, but only if serum iron was high-normal. Oxygen carriage was lower if iron deficiency was present (median 16.1 [IQR 14.7, 18·1] mls/dL compared to 19.0 [IQR $17 \cdot 4,20 \cdot 2] \mathrm{mls} / \mathrm{dL}, \mathrm{p}<0.0001$ ), implying $\sim 15 \%$ higher cardiac outputs were required to maintain oxygen delivery. At rest, this was not met by a higher pulse in the iron deficiency group, indicating stroke volume would need be higher. Self reported exercise tolerance was used as a crude indicator of whether compensating for reduced oxygen carriage was achievable in this patient group. There was a very clear inverse correlation between exercise grade and oxygen carriage such that exercise tolerance was worse in patients with lower oxygen carriage (coefficient -0.0012 (95\% CI -0.0017 , $-0.00061) \mathrm{p}<0.0001)$. The trend was evident across all grades of exercise tolerance.

Conclusions Low oxygen carriage per unit volume, and not low $\mathrm{PaO}_{2} / \mathrm{SaO}_{2}$ per se, are predictors of impaired exercise tolerance in PAVM patients.

\section{S43 DYSPNEA AND EXERCISE CAPACITY ARE NOT RELATED TO ARTERIAL HYPOXEMIA IN THE ABSENCE OF ALVEOLAR HYPOXIA: PROSPECTIVE STUDIES IN PATIENTS WITH PULMONARY ARTERIOVENOUS MALFORMATIONS}

V Santhirapala, LSG Howard, K Murphy, B Mukherjee, M Busbridge, HC Tighe, JMB Hughes, JE Jackson, CL Shovlin; Imperial College London, London, UK

\subsection{6/thoraxjnl-2013-204457.50}

Background Low blood oxygen concentrations (hypoxaemia) usually result from alveolar hypoxia which also stimulates hypoxic pulmonary vasoconstriction, thereby increasing right ventricular work. In contrast, anatomic right-to-left shunts such as pulmonary arteriovenous malformations (PAVMs), cause hypoxaemia without alveolar hypoxia. Our aim was to test whether isolated arterial hypoxaemia is associated with dyspnoea or impaired exercise capacity.

Methods Two prospective studies were performed in patients with radiologically-proven PAVMs. Exercise tolerance was graded by a modified MRC dyspnoea scale. Other patient variables were quantified at rest and on exercise.

Results In 165 consecutive patients, aged 17-87 (median 49)ys, resting $\mathrm{SaO}_{2}$ varied widely (78.5-99\%, median 95\%). Five patients were athletes, despite severe resting hypoxaemia $\left(\mathrm{SaO}_{2}<85 \%\right)$. $\mathrm{SaO}_{2}$ displayed no clear relationship with dyspnoea grade. Higher grade dyspnoea was significantly more common in patients with coexisting cardiorespiratory disease who were more likely to report symptomatic improvement post embolisation. During cardiopulmonary exercise testing, $21 \mathrm{PAVM}$ patients $\left(\mathrm{SaO}_{2} 80-96 \%\right)$ were no more dyspnoeic than 12 age-matched volunteers $\left(\mathrm{SaO}_{2}\right.$ 96-99\%). Within the 21 PAVM patients, the majority achieved their predicted workload and peak $\mathrm{VO}_{2}$, and there was no difference in maximum workload, or peak $\mathrm{VO}_{2}$ according to the severity of hypoxemia. PAVM patients demonstrated similar relationships betweenpeak heart rate and peak $\mathrm{VO}_{2}$ as controls. For five patients retested post embolisation, when $\mathrm{SaO}_{2}$ rose from $88-94 \%$ to $94-96 \%$ $(p=0.009)$, there was no difference in perceived dyspnoea, maximum workload (medians 119/113W) or peak $\mathrm{VO}_{2}$ (medians 1.69/ $1.72 \mathrm{Lmin}^{-1}$ ). Treated patients reset to virtually identical peak oxygen pulse following embolisation. Overall, workload and peak $\mathrm{VO}_{2}$ were associated not with oxygenation parameters, but with body mass index, anaerobic threshold and ventilatory efficiency: Expired end-tidal $\mathrm{PCO}_{2}$ at rest and on peak exercise was lower in PAVM patients compared to controls, and in the more hypoxemic patients. During exercise, PAVM patients increased minute ventilation (V'E) more than controls for a given increase in $\mathrm{CO}_{2}$ output $\left(\mathrm{V}^{\prime} \mathrm{CO}_{2}\right)$, and post embolisation, end-tidal $\mathrm{PCO}_{2}$ and $\mathrm{V}^{\prime} \mathrm{E} / \mathrm{V}^{\prime} \mathrm{CO}_{2}$ slopes normalised.

Conclusions Despite severe hypoxaemia, normal oxygen delivery can be maintained during peak exercise by harnessing integrated adaptive responses that maintain oxygen delivery and uptake with each heart beat (the "O $\mathrm{O}_{2}$ pulse"). 